Pacific Journal of Mathematics

ON THE CONSTRUCTION OF LOWER RADICAL PROPERTIES 


\title{
ON THE CONSTRUCTION OF LOWER RADICAL PROPERTIES
}

\author{
YU-LEE LEE
}

\begin{abstract}
The purpose of this paper is to give a simple construction of the lower radical properties for an arbitrary class of rings.
\end{abstract}

Let $\mathscr{S}$ be a class of rings. We shall say that the ring $R$ is an $\mathscr{S}$-ring if $R$ is in $\mathscr{S}$. An ideal $J$ of $R$ will be called an $\mathscr{S}$-ideal if $J$ is an $\mathscr{S}$-ring. A ring which does not contain any nonzero $\mathscr{S}$-ideals will be called $\mathscr{S}$-semisimple. We shall call $\mathscr{S}$ a radical property if the following three conditions hold:

(A) homomorphic image of an $\mathscr{S}$-ring is an $\mathscr{S}$-ring,

(B) every ring $R$ contains a largest $\mathscr{S}$-ideal $S$,

(C) the quotient ring $R / S$ is $\mathscr{S}$-semi-simple.

The largest $\mathscr{S}$-ideal $S$ of a ring $R$ is called the $\mathscr{S}$-radical of $R$.

Given a class of rings $\mathscr{A}$, Kurosh has constructed a lower radical property $\mathscr{S}(\mathscr{A})$ determined by $\mathscr{A},[1],[2]$, i.e., $\mathscr{S}(\mathscr{A})$ is a radical property, $\mathscr{A} \cong \mathscr{S}(\mathscr{A})$, and if $\mathscr{T}$ is any radical property and $\mathscr{A} \cong$ $\mathscr{T}$ then $\mathscr{S}(\mathscr{A}) \subseteq \mathscr{T}$.

In this paper we are going to give a simpler construction.

The construction is similar to [3], where we take $\mathscr{A}$ to be the class of all nilpotent rings. It is proven in [3] that this construction is exactly the lower radical property determined by the class of nilpotent rings. We want to extend this construction to any class of rings.

Let $\mathscr{A}$ be a class of ring and let $\mathscr{A}_{0}$ be the class of all homomorphic images of rings in $\mathscr{A}$. For each ring $R$, let $D_{1}(R)$ be the set of all ideals of $R$, and by induction, we define $D_{n+1}(R)$ to be the family of all rings which are ideals of some ring in $D_{n}(R)$ and set

$$
D(R)=\cup\left\{D_{n}(R): n=1,2,3, \cdots\right\} .
$$

A ring $R$ is called a $\mathscr{L}(\mathscr{A})$-ring if $D(R / I)$ contains a nonzero ring which is isomorphic to a ring in $\mathscr{A}_{0}$ for each ideal $I$ of $R$ and $I \neq R$. The following facts are clear.

Lemma 1. $\mathscr{A} \subseteq \mathscr{A} \cong \subseteq \mathscr{L}(\mathscr{A})$.

Lemma 2. If $I$ is an ideal of $R$ then $D(I) \subseteq D(R)$.

LemMa 3. Every isomorphic image of an $\mathscr{L}(\mathscr{A})$-ring is an $\mathscr{L}(\mathscr{A})$-ring. 
Lemma 4. If $A$ is isomorphic to $B$ and $D(A)$ contains a ring which is isomorphic to a nonzero ring in $\mathscr{A}_{0}$ then so does $D(B)$.

Lemma 5. If $\mathscr{A} \cong \mathscr{B}$ then $\mathscr{L}(\mathscr{A}) \cong \mathscr{L}(\mathscr{B})$.

Also we need the following fact [1].

Lemma 6. A class of rings $\mathscr{S}$ is a radical property if and only if

(A) A homomorphic image of an $\mathscr{S}$-ring is an $\mathscr{S}$-ring.

(D) If every nonzero homomorphic image of a ring $R$ contains a nonzero $\mathscr{S}$-ideal, then $R$ is an $\mathscr{S}$-ring.

Lemma 7. If $\mathscr{S}$ is a radical property, then for any ring $R$ and any ideal $I$ of $R$, the S-radical of $I$ is an ideal of $R$.

Theorem 1. If $\mathscr{A}$ is a class of rings, then $\mathscr{L}(\mathscr{A})$, contructed above, is a radical property.

Proof. If $R$ is in $\mathscr{L}(\mathscr{A})$ and $I$ is any ideal of $R$. Consider the quotient ring $R / I$ and any proper ideal $J / I$ of $R / I, R / I / J / I \cong R / J$.

By definition, $D(R / J)$ contains a ring which is isomorphic to a nonzero ring in $\mathscr{A}_{0}$ and therefore so does $D(R / I / J / I)$, and hence $R / I$ is in $\mathscr{L}(\mathscr{A})$. Every homomorphic image of $R$ is isomorphic with $R / I$ for some $I$. Hence, by Lemma 3, (A) follows.

Suppose that every nonzero homomorphic image of $R$ contains a nonzero $\mathscr{L}(\mathscr{A})$-ideal and let $I$ be any ideal of $R$ and $I \neq R$. Then $R / I$ contains a nonzero $\mathscr{L}$-ideal $J / I$. Now $D(J / I) \subseteq D(R / I)$, hence $D(R / I)$ contains a ring which is isomorphic to a nonzero ring in $\mathscr{A}$. By definition of $\mathscr{L}(\mathscr{A}), R$ is in $\mathscr{L}(\mathscr{A})$. This proves $(D)$. By Lemma $6, \mathscr{L}(\mathscr{A})$ is a radical property.

THEOREM 2. If $\mathscr{T}$ is a radical property then $\mathscr{L}(\mathscr{T})=\mathscr{T}$.

Proof. By Lemma 1, $\mathscr{T} \cong \mathscr{L}(\mathscr{T})$.

If there is a ring $R$ in $\mathscr{L}(\mathscr{T})$ but not in $\mathscr{T}$, let $I$ be $\mathscr{T}$-radical of $R$. Then $R / I$ is a nonzero ring in $\mathscr{L}(\mathscr{T})$ and is $\mathscr{T}$-semi-simple. Without loss of generality we may assume $R$ is in $\mathscr{L}(\mathscr{T})$ but is $\mathscr{T}$-semi-simple. By definition $D(R)$ contains a ring $J \neq 0$ such that $J \in \mathscr{T}$. But if $K$ is a nonzero ideal of $R$, i.e., $K \in D_{1}(R)$, then, by Lemma 7, the $\mathscr{T}$-radical of $K$ is also an ideal of $R$. But $R$ is $\mathscr{T}$ simi-simple. Hence $K$ is also $\mathscr{T}$-semi-simple. By induction it is easy to see every ring in $D(R)$ is $\mathscr{T}$-semi-simple. This is a contradiction. Hence $\mathscr{T}=\mathscr{L}(\mathscr{T})$. 
THEOREM 3. If $\mathscr{A}$ is a class of rings then $\mathscr{L}(\mathscr{A})$ is the lower radical property determined by $\mathscr{A}$.

Proof. Let $\mathscr{S}$ be any radical property such that $\mathscr{A} \cong \mathscr{S}$. Then by Theorem 2 and Lemma $5 \mathscr{S}=\mathscr{L}(\mathscr{S}) \supseteqq \mathscr{L}(\mathscr{A})$.

\section{BIBLIOGRAPHY}

1. N. J. Divinsky, Rings and radicals, University of Toronto Press, 1965.

2. A. G. Kurash, Radicals of rings and algebras, Mat. Sbornik (1953).

3. Y. L. Lee, A characterization of Baer lower radical property, Kyungpook Math. J. 7 (1967).

Received January 19, 1968. Presented to the Society on January 26, 1967.

Kansas State UNiversity

MANHATTAN, KANSAS 



\section{PACIFIC JOURNAL OF MATHEMATICS}

\section{EDITORS}

H. ROYDEN

Stanford University

Stanford, California

\section{R. $R$ PHELPS}

University of Washington

Seattle, Washington 98105

\section{J. DugunduI}

Department of Mathematics

University of Southern California

Los Angeles, California 90007

RICHARD ARENS

University of California

Los Angeles, California 90024

\section{ASSOCIATE EDITORS}

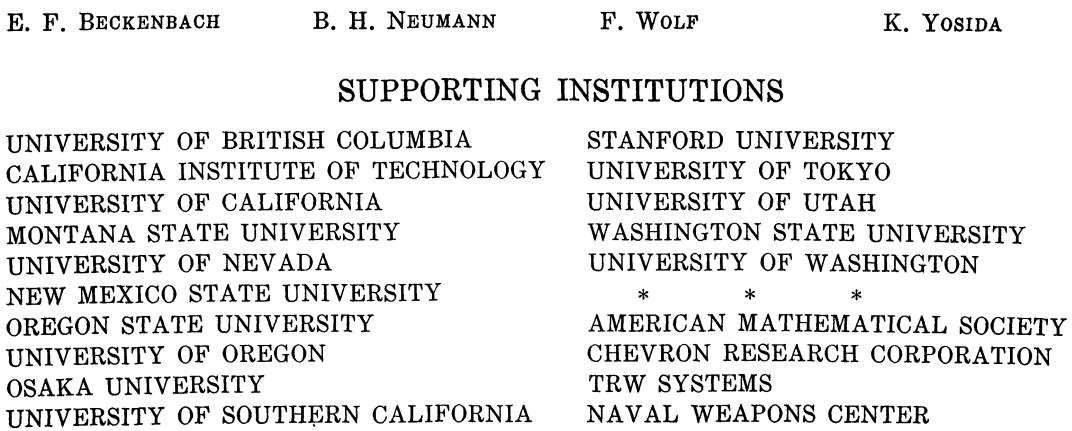

The Supporting Institutions listed above contribute to the cost of publication of this Journal, but they are not owners or publishers and have no responsibility for its content or policies.

Mathematical papers intended for publication in the Pacific Journal of Mathematics should be in typed form or offset-reproduced, double spaced with large margins. Underline Greek letters in red, German in green, and script in blue. The first paragraph or two must be capable of being used separately as a synopsis of the entire paper. It should not contain references to the bibliography. Manuscripts, in duplicate if possible, may be sent to any one of the four editors. Please classify according to the scheme of Math. Rev. 36, 1539-1546. All other communications to the editors should be addressed to the managing editor, Richard Arens, University of California, Los Angeles, California, 90024.

50 reprints are provided free for each article; additional copies may be obtained at cost in multiples of 50 .

The Pacific Journal of Mathematics is published monthly. Effective with Volume 16 the price per volume (3 numbers) is $\$ 8.00$; single issues, $\$ 3.00$. Special price for current issues to individual faculty members of supporting institutions and to individual members of the American Mathematical Society: $\$ 4.00$ per volume; single issues $\$ 1.50$. Back numbers are available.

Subscriptions, orders for back numbers, and changes of address should be sent to Pacific Journal of Mathematics, 103 Highland Boulevard, Berkeley, California, 94708.

PUBLISHED BY PACIFIC JOURNAL OF MATHEMATICS, A NON-PROFIT CORPORATION

Printed at Kokusai Bunken Insatsusha (International Academic Printing Co., Ltd.), 7-17, Fujimi 2-chome, Chiyoda-ku, Tokyo, Japan. 


\section{Pacific Journal of Mathematics}

Vol. 28, No. $2 \quad$ April, 1969

Richard Arens and Donald George Babbitt, The geometry of relativistic

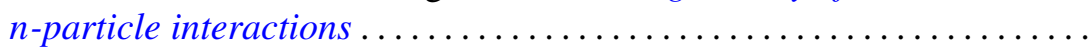

Kirby Alan Baker, Hypotopological spaces and their embeddings in lattices

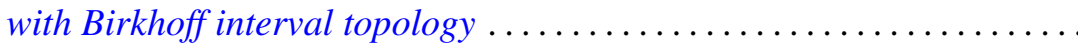

J. Lennart (John) Berggren, Finite groups in which every element is conjugate to its inverse ........................... 289

Beverly L. Brechner, Homeomorphism groups of dendrons . . . . . . . . . . . 295

Robert Ray Colby and Edgar Andrews Rutter, QF - 3 rings with zero singular ideal ................................. 303

Stephen Daniel Comer, Classes without the amalgamation property....... 309

Stephen D. Fisher, Bounded approximation by rational functions ......... 319

Robert Gaines, Continuous dependence for two-point boundary value problems..................................... 327

Bernard Russel Gelbaum, Banach algebra bundles ............... 337

Moses Glasner and Richard Emanuel Katz, Function-theoretic degeneracy criteria for Riemannian manifolds ...................... 351

Fletcher Gross, Fixed-point-free operator groups of order $8 \ldots \ldots \ldots \ldots 357$

Sav Roman Harasymiv, On approximation by dilations of distributions . . . . 363

Cheong Seng Hoo, Nilpotency class of a map and Stasheff's criterion ... . . 375

Richard Emanuel Katz, A note on extremal length and modutus.......... 381

H. L. Krall and I. M. Sheffer, Difference equations for some orthogonal polynomials ................................

Yu-Lee Lee, On the construction of lower radical properties ........... 393

Robert Phillips, Liouville's theorem........................... 397

Yum-Tong Siu, Analytic sheaf cohomology groups of dimension $n$ of

n-dimensional noncompact complex manifolds ..... . .

Michael Samuel Skaff, Vector valued Orlicz spaces. II...

James DeWitt Stein, Homomorphisms of $B^{*}$-algebras .... . .

Mark Lawrence Teply, Torsionfree injective modules .... . . .

Richard R. Tucker, The $\delta^{2}$-process and related topics. II .

David William Walkup and Roger Jean-Baptiste Robert Wets, Lifting

projections of convex polyhedra...

Thomas Paul Whaley, Large sublattices of a lattice. 